\title{
\begin{tabular}{l|l} 
Arts & Lines of Resistance
\end{tabular} Forum
}

\section{Rose Butler}

www.rosebutler.com

rose@rosebutler.com

\section{Introduction to the Artist}

Rose Butler is an artist, researcher, and senior lecturer in Fine Art at Sheffield Hallam University, UK. She uses adapted technology and custom-built software alongside early cameras and analogue techniques to make interactive installations, multi-screen videos, or large-scale photographs. She is writing up a doctoral study that centres on surveillance and considers the ethics and politics of looking through arts practice. By bringing together political commentary, personal account, and fiction in her research, she examines the narratives that surround and shape us. Her work traces a long observation in the Houses of Parliament of the Investigatory Powers Bill in 2016, followed by research at the Stasi Records Agency, Berlin, into film and photographic surveillance material from hidden cameras. Butler exhibited Come \& Go, an interactive dance installation, at the Millennium Galleries, Sheffield, June to September 2017 and received an award for this work as part of the Surveillance Studies Arts Prize 2018. Her work was exhibited at Decad, Berlin, November 2019 to January 2020 and will be exhibited at NeMe Arts Centre, Cyprus, in 2020. In 2019, she presented her research at NAFAE Living Research: The Urgency of the Arts, Royal College of Art, March 2019; Free and Open Source Technologies, Arts and Commoning Practices: An Unconference about Art, Design, Technology, Making, Cities and Their Communities, University of Nicosia Research Foundation, Cyprus, May 2019; Creative Interruptions: A Festival of Arts and Activism, British Film Institute, June 2019; and Uncertainty, Turbulence and Moving Image Archives, University College London, June 2019.

This was the first year of the arts prize within the Surveillance Studies Network (SSN) conference. I felt privileged to have received an honorary mention for my work Come \& Go (2017) and to have the opportunity to present during one of the sessions. I understood that the intention of launching an arts prize was to expand the field of research by carving out a space for arts practices in relation to the field of surveillance studies, and I am interested in the ways in which art practice contributes towards broader scholarly fields and the different approaches artists might take.

I am going to discuss a body of work titled Lines of Resistance (2014), made over two years, that acted as a preamble to my doctoral study, and then introduce my current doctoral research. This personal account describes the development of playful experimental works into a piece of academic research of individual and cultural relevance. I describe a responsive, visual, sensorial process, which is supported by and extended through critical reading, technology, and experimentation. Throughout this text, I use the term "art practice" to refer to art made by contemporary visual artists. This includes work by artist researchers carrying out practice-based research inside academia as well as artists with practices across media working outside of an academic framework. My work straddles both of these ways of working, work that sits within an academic 
framework alongside preparatory or experimental art that falls outside the frameworks of art-making as research. ${ }^{1}$

Lines of Resistance consists of two large photographic panoramas of undeveloped areas of the death strip, which is the former German Democratic Republic patrolled zone on the border of East Berlin. A video filmed at the Berlin Wall Memorial site is also part of this body of work. To make work, my process often involves getting access to a restricted area, to have a look, to be able to see or find out more, and to learn something by doing so. I use a camera as the vehicle with which to look closely and from which to have a reason to look over a period of time. When I describe my art practice in this way, it seems to make sense why my doctoral research now centres on surveillance. Surveillance, though, suggests someone in a position of power, with access and authorisation to look alongside the technology or means to enable that. As an artist I do not have that, but my research involves getting access to look, at surveillance, with adapted use of technology and sometimes with the authorisation to do so.

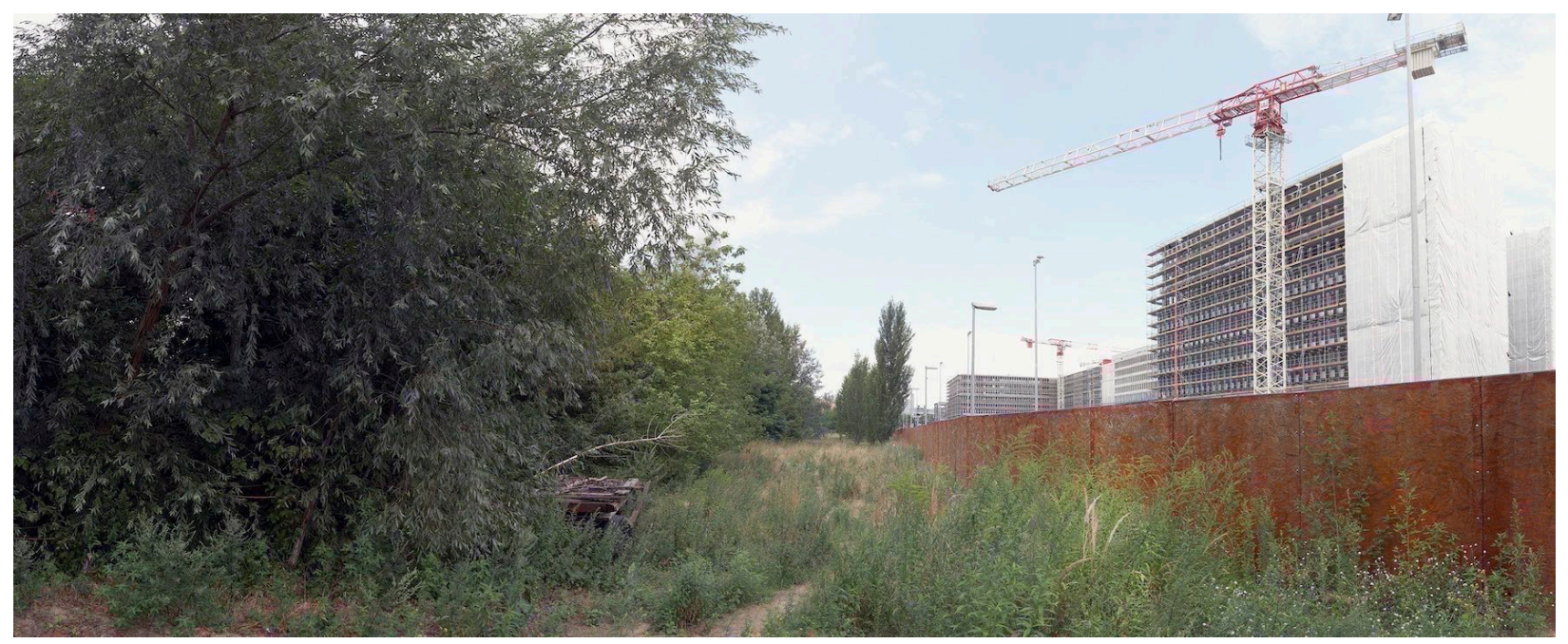

Figure 1: Chausseestrasse 2014, Digital composite panorama $4 \mathrm{~m} \times 1.5 \mathrm{~m}$

These photographic panoramas (and video-see website ${ }^{2}$ ) examine historical, decommissioned surveillance structures within a space of reunification following the end of the Cold War. The Berlin Wall Memorial Site with its hard borders, watch towers, and patrolled zone offers a historical perspective on the theme of surveillance and control. In the twenty-eight years that the wall was in place during the Cold War, the patrolled zone was a no man's land between the two walls of the border. It was an extensive space under militarily controlled stasis, framed by the political forces of opposing ideologies. Now decommissioned following the 1989 Peaceful Revolution and reunification of Germany, parts of the wall have been preserved, are abandoned, or are being redeveloped. The Berlin Wall Memorial research and education centre affords the viewer an opportunity to study and comprehend the methods used to seal the border.

The panorama "Chausseestrasse" was made while experimenting with a Gigapan, which was new technology at the time. A Gigapan is an automated tripod head that pans, tilts, rotates, and releases the shutter within defined parameters. You visually set the top left image of documentation and the bottom right, the device then automates the tripod head to take the image series line by line. The camera took twenty minutes to photograph 144 images. These were then digitally stitched in accompanying software and then

1 This is a simplified description of a complex definition. For a comprehensive analysis of this term, see Sullivan 2010.

$2 \mathrm{http} / / / \mathrm{www} \cdot$ rosebutler.com/projects/lines-resistance 
corrected in postproduction. The size of this uncompressed digital-composite image is $4 \mathrm{~m} \times 1.5 \mathrm{~m}$. I later discovered that Gigapan is a technology that was developed by Google and NASA to take high resolution panoramas of Mars using remote control. Forensic scientists adapted this technology for use at crime scenes. The high resolution image produced by Gigapan allows a detailed digital analysis to uncover evidence that might not be apparent to the naked eye.

It was the pictorial qualities within this image that gained my attention: the flowers, the meandering path, and the height of the wall intentionally restricting the view, alongside the contrast of the building site. While taking the photographs to make Chausseestrasse, I was balancing on a tripod I had made from pieces of timber to look over the wall, and a man passing by told me that the building behind the wall would be the new German secret service building.

The image spans the old and new materials of state surveillance: the historical decommissioning of the death strip in the left of the image is in a state of flux, having been abandoned and taken over by undergrowth in the years following the Peaceful Revolution (1989). On the right of the image, the building site of the new German Federal Intelligence Service presents the re-commissioning of state surveillance in the years following the revolution. The image documents an ambiguous, transitional space, where historical and contemporary political states overlap. In this image, both of these sites of surveillance are in an interstitial state and the image presents a collision of temporalities, surveillance takes the place of the former border walls of the East and the West, and in-between is a wasteland, disarray, a scar, a crime scene. The image presents evidence of the rise and fall of state control, the use of surveillance to support state power, and through this speaks of the rhythm of politics and resistance. In February 2019, the world's biggest intelligence headquarters finally opened, twelve years after construction began.

I did not know at the time that I was using technology originally developed by NASA and adapted by crime forensics to photograph the largest secret service agency in the world. This intuitive haphazard process of discovering and photographing this site enabled the production of an important image in the development of my research. The method of "following your nose" and responding to intuition is integral to my creative process. Intuition, imagination, spontaneity, or tacit knowledge are techniques that we might consider immeasurable, ill-defined, or unspecific; they are vague and responsive or involve some risk-taking through leaps of faith, prompts, or cues (Cocker 2013; Sullivan 2010; Rose 2016). It is through these speculative techniques operating in a space of uncertainty, intervention, playfulness, or emotional response that artists and their works can open up new understanding through the very process of creation. As such, art research can produce and generate new forms of analyses and further knowledges. The body of formative experimental works, Lines of Resistance, acted as preparatory research that informed a proposal for doctoral study. Embedded within the study is a commentary on the overlap and repetition of surveillance narratives: the historical reappraisal of state surveillance made possible by research at the Stasi Records Agency and an observation of the contemporary extension of new state surveillance capabilities through the UK Investigatory Powers Act. As we enter the third year of the political uncertainty following the EU referendum in the UK, I have begun to think of this in-between space, stasis, a wasteland, or the state of limbo to support state power, as Brexit, which happened in the middle of my observation of the bill in parliament.

As part the doctoral research, I spent eight months observing the Investigatory Powers Act (a.k.a. "The Snooper's Charter"), which is new digital surveillance legislation that passed through the UK Houses of Parliament in November 2016. While observing the debate, I took photographs in Parliament on a Minox Cold War spy camera and recorded audio on a 1980s Dictaphone. This was a method for a close and detailed observation that would also generate material to make artworks in order to extend my understanding and expand my research through different presentation forums. The debate centred on the balance between privacy and security, and one of the recurring rationales for the legislation was the necessity to keep up to date with technological advance. 
I then carried out research into camera technique and training at the Stasi Film and Video Archive and analysed historical footage from hidden cameras. The Stasi Records Agency in Berlin emphasises that the power of surveillance does not lie within technology itself but in the governance and authorisation of its use. This research is ongoing and has been presented at four conferences in 2019 and will be exhibited in two forthcoming exhibitions.

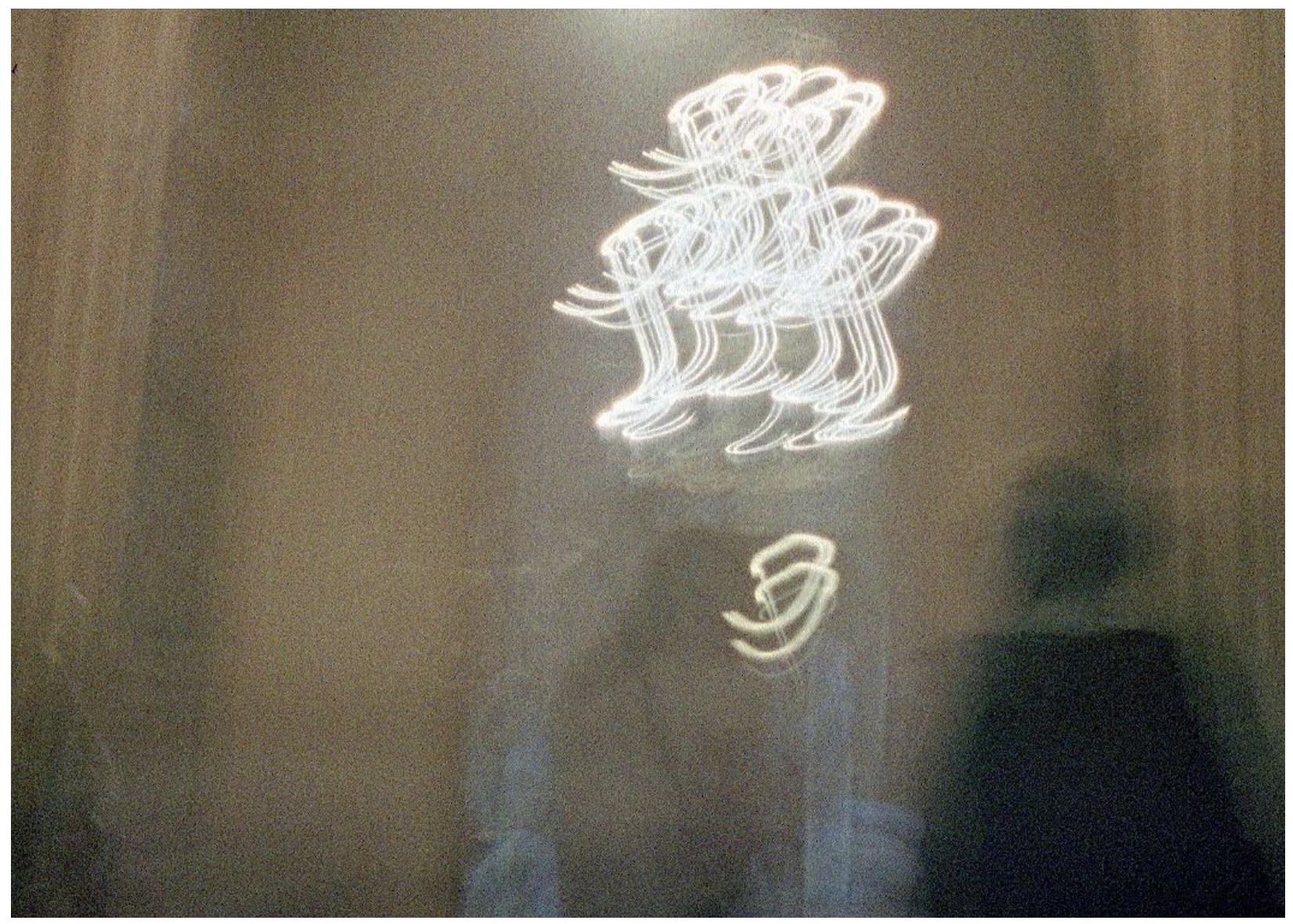

Figure 2: Houses of Parliament, UK. June 2016; Image taken on a Minox Complan C-Type Print 60" x 85"

My art practice or art making as research uses the framework of specific technologies to bring together the how and what of surveillance representations. Discussions during various sessions at the SSN 2018 conference outlined a lack of technical knowhow as problematic when critiquing surveillance technology. We cannot assess, critique, or realise the potential of technology without a basic understanding of how it works, the origins of its use, and its potential for repurposing. Without a feel for the material qualities of surveillance technology, our understanding and experience of the use, application, or potential is limited.

During the debate on the Investigatory Powers Bill, June to November 2016, there were many examples in both the House of Commons and the House of Lords of technological misunderstanding or vague impressions of the use and potential of digital technologies (including gaming forums, the dark web, social media, the internet ${ }^{3}$ ). These confusions occurred despite the committee stage of the bill's passage having

${ }^{3}$ Lord King of Bridgewater (Con) is an "avowed ignoramus" when it comes to new technologies. But despite acknowledging that, he continued to speak to technologies' use ignorantly: "while it might seem to be an amusing paradise for geeks, we know that there is a very dark side to this and that it offers a huge range of opportunities for 
received written reports from seventy-one external bodies, that according to Theresa May (as Home Secretary) made a pile of paperwork over a foot high.

A gap in technical understanding and knowledge of the material qualities and potential of surveillance technologies creates the opportunity for hiding misuse and subverting democratic process, as was recently exposed during the Cambridge Analytica and Facebook scandal. In March 2018, Channel 4 released two broadcasts that included undercover filming of meetings arranged with Cambridge Analytica directors; the cameraman was posing as a client from Sri Lanka. In the second broadcast on 20 March 2018, CEO Alexander Nix was caught on camera describing his response to questioning by the House Intelligence Committee (USA), to whom he gave evidence in 2017. He belittled the questioning by representatives and stated, "They're politicians, they're not technical. They don't understand how it works."

Unfortunately for Alexander Nix, he had forgotten how the technology of undercover cameras works. The examples of politicians across continents not understanding technology or "the internet" reached a peak as the Cambridge Analytica scandal unfolded and Facebook CEO Mark Zuckerberg was called before US Congress to explain the use of private data gathered by Cambridge Analytica in the Trump election campaign. Various videos of the questioning appeared on Facebook and Twitter with users commenting that it was like trying to help their grandparents with their computer. ${ }^{5}$

In the current political climate with growing global populism in the politics of the far right, it is essential that specialisms are brought together to generate informed interdisciplinary understanding. The opportunities for use and exploitation of surveillance technologies presented through the speed of technological development, alongside a general lack of technical understanding to support oversight, and the slow progress of the care and detail of legislation are a threat to our democratic freedoms and human rights.

Art that examines surveillance is often accompanied by a knowledge of, interest in, and use of the technologies and material qualities of surveillance. ${ }^{6}$ Through this practical and tangible understanding, artists are equipped to present a critique of the politics and ethics surrounding surveillance technologies. This understanding is illustrated through various forums, predominantly a gallery exhibition coupled with artist talks and catalogue publications to expand the discussion surrounding the art. The results of this research process are disseminated and expanded through conference, writing, journal review, symposium, and publication. Many artists no longer confine their practices to a particular style and technique, but use their methods and media to address broader questions of political, human, and cultural concern. Curator Alfredo Cramerotti (2015) describes the wealth of artists addressing social and geopolitical issues and presents a situation where the urgency of issues is so great that it makes it impossible to leave these concerns outside their own arts practice. He describes art that tries to expose or make things visible as an emergent mode of investigative journalism; art as a way to shape a new language. But whereas investigative journalists take, expand, and re-present an existing narrative, artists research, expand, and create an entirely new narrative by means of an artwork. Artists David Cotterrell and Ruwanthie de Chickera (2018) describe artists

some very sinister elements, be they terrorists, organised criminals, paedophiles or child abusers. All forms of evil can survive and operate within this.” Lord King of Bridgewater; Official Report, Lords, 27/06/16; col. 1372.

4 See full broadcast at https://www.channel4.com/news/exposed-undercover-secrets-of-donald-trump-data-firmcambridge-analytica.

5 Some of the questions to Zuckerberg included: "Is Twitter the same as what you do?" (South Carolina Senator Lindsey Graham [R]); "If I'm emailing within WhatsApp ... does that inform your advertisers?" (Hawaii Senator Brian Schatz [D]); "How do you sustain a business model in which users don't pay for your service?" (Utah Senator Orrin Hatch [R]); the full five-hour testimony can be found at https://www.youtube.com/watch?v=pXq-5L2ghhg.

${ }^{6}$ For examples, reference artists, academics, and researchers from Lawrence Abu Hamden and James Bridle to Ayesha Hammed, Manu Luksch, Jill Majid, Trevor Paglen, Hito Steyerl, or the collective work of Forensic Architecture, to name a few. 
as working with a journalistic sensitivity, in that they are able to "shift tack in response to the world around us."

The process of making, developing, and critiquing art enables us to develop and expand upon ideas and to look in new ways. The detail of making the image Chausseestrasse and the methods I use in documenting the events in Parliament describe the process of knowledge production through art making. By generating creative, subjective insights grounded in individual experience, I, as well as other artists, can present interactions that can be encountered in alternative ways and over diverse forums. Scholar Torin Monahan (2018) discusses the ways in which specific surveillance art activates the viewer to "create a space for ideological critique." Furthermore, he discusses the potential of "fostering ambiguity and decentring the viewing subject" within the works of art themselves. Through interdisciplinarity, artists recreate the space of the viewing subject, which would support the task posited by Monahan of "extending states of dis-ease beyond momentary encounters with artworks or installations" (17).

The UK is the most surveilled democratic country in the West. The 2016 EU referendum and continuing fallout has exposed the threats to individual freedom, democratic process, and human rights. There is a long history of artists ${ }^{7}$ across continents making work about surveillance, and bringing artists into the SSN is an opportunity for expanded interdisciplinary understanding. This creates the potential to expose the limitations of research rooted in more conventional scholarly means. And by acknowledging these limitations we can expand understanding. Art can offer a range of subjective insights, creating ambiguous spaces to be selfcritical and offering to bridge understanding between culture and politics. We continue to work across disciplines and define art as research in order to preserve the freedom to carry out research within the language of art making.

\section{References}

Cocker, Emma. 2013. Tactics for Not Knowing: Preparing for the Unexpected. In On Not Knowing: How Artists Think, edited by Elizabeth Fisher and Rebecca Fortnum, 126-35. London: Black Dog.

Cotterrell, David, and Ruwanthie de Chickera. 2018. Transmission Lecture Series. Lecture, from Sheffield Hallam University, Sheffield, UK, 13 November 2018. https://www.sitegallery.org/event/transmission-2/

Cramerotti, Alfredo. 2015. Together to Explain Why an Action is Continuing: Still Yet. Presentation, from SAIC (School of the Art Institute of Chicago), 16 September 2015. https://vimeo.com/148882168 [accessed December 6, 2018].

Monahan, Torin. 2018. Ways of Being Seen: Surveillance Art and the Interpellation of Viewing Subjects. Cultural Studies 32 (4): $560-81$.

Rose, Gillian. 2016. Visual Methodologies: An Introduction to Researching with Visual Methodologies. 4th ed. London: Sage.

Sullivan, Graeme. 2010. Art Practice as Research: Inquiry in Visual Arts. 2nd ed. Los Angeles: Sage.

Thompson, Nato. 2015. Seeing Power: Art and Activism in the 21st Century. London: Melville House.

\footnotetext{
${ }^{7}$ For examples, reference artists, academics, and researchers from Lev Manovich and Nam June Paik to Lawrence Abu Hamden, Zach Blas, Ruth Catlow, David Cotterrell, Ayesha Hameed, Manu Luksch, Jill Magid, Trevor Paglen, Hito Steyerl, and Thomson and Craighead, to name a few.
} 